\title{
Effects of Organic Salts on Dynamic Mechanical Properties of Styrene Ionomers
}

\author{
Yeon Hwa NaH, Hee-Seok KIm, Joon-Seop KIm, ${ }^{\dagger}$ Whangi KIm, ${ }^{*}$ \\ and Yeonhee LEE** \\ Department of Polymer Science \& Engineering, Chosun University, \\ Kwangju 501-759, Korea \\ * Department of Chemistry, Kun-Kuk University, Chungju 380-701, Korea \\ **Advanced Analysis Center, Korea Institute of Science and Technology, \\ Seoul 130-650, Korea
}

(Received May 22, 1998)

KEY WORDS Ionomer / Styrene / Organic Salt / Plasticization / Blends / Filler /

Polymers of low dielectric constants, containing relatively small amounts of ionic comonomers, frequently show microphase-separation. ${ }^{1,2}$ This is caused by ion aggregation within the relatively nonpolar matrix. It is generally accepted that ion-pairs aggregates form quadruplets, sextuplets, and higher aggregates, called multiplets. ${ }^{3}$ Ion aggregation leads to reduction in the mobility of surrounding matrix segments. At high ion concentrations, overlap of the restricted mobility regions occurs and gives rise to larger contiguous regions, called clusters, ${ }^{4}$ in which the material exhibits a second glass transition temperature $\left(T_{\mathrm{g}}\right)$ higher than that of the matrix $T_{\mathrm{g}}$.

Since ionomers have nonpolar matrix regions and polar multiplets, the selective plasticization of ionomers should be possible. ${ }^{2,5}$ A plasticizer affects selectively either multiples or a matrix phase, or both. Thus, we can choose plasticizers to achieve particular properties of ionomers.

Recently, Kim et al. ${ }^{6}$ found that the addition of sodium dodecylbenzenesulfonate, SDBS, to sodium sulfonated polystyrene ionomers resulted in large decrease in the cluster $T_{\mathrm{g}}$. The matrix $T_{\mathrm{g}}$ decreased only slightly. The presence of the SDBS molecules thus led to plasticization of the ionic clusters. This preferential plasticization is the result of incorporation of ionic groups of SDBS molecules into multiplets, with nonpolar alkyl chains of SDBS residing in the reduced mobility regions. Orler et $a l .^{7}$ compared the plasticization effects of sodium benzenesulfonate (SBS) to those of SDBS in sulfonated polystyrene ionomers. They found that the SBS depresses the cluster $T_{\mathrm{g}}$ slightly without affecting the matrix $T_{\mathrm{g}}$, and that decrease in the cluster $T_{\mathrm{g}}$ is less in systems plasticized with the SDBS. Tong and Bazuin ${ }^{8}$ observed an unusual plasticization effect on the properties of poly(ethyl acrylate-co-sodium acrylate) ionomers plasticized with sodium hexadecanoate. Sodium hexadecanoate was crystalline and remained phase-separated when mixed with the ionomer, and phase-separated organic salts acted as merely filler.

In the present study, we explore the effects of changing a carboxylate ionic group to a sulfonate ionic group and the effects of the amounts of organic salts. Thus, taking

\footnotetext{
† To whom correspondence should be addressed.
}

poly(styrene-co-sodium methacrylate) ionomer as the first system, comparison is made between dynamic mechanical properties of ionomers mixed with sodium $p$ toluate (Tol) and sodium $p$-toluenesulfonate (Sul) salts. Then, we take poly(styrene-co-sodium styrenesulfonate) ionomer as the second system, and compare the properties of ionomers containing Tol salts to those of ionomers containing Sul salts. The dependence of clustering on filler effects is addressed briefly.

\section{EXPERIMENTAL}

\section{Sample Preparation}

Two poly(styrene-co-methacrylic acid) samples were prepared by bulk free radical polymerization of styrene and methacrylic acid monomers. Polystyrene $(\mathrm{MW}=$ ca. 300000) was also prepared by bulk free radical polymerization. The sulfonation method developed by Makowski et al. ${ }^{9}$ was used to produce the poly(styreneco-styrenesulfonic acid) samples. To determine ion content, the samples were dissolved in a benzene-methanol $(9: 1, \mathrm{v} / \mathrm{v})$ mixture to make a $5 \%(\mathrm{w} / \mathrm{v})$ solution, and titrated with standard methanolic $\mathrm{NaOH}$ to the phenolphthalein end point. The acid content of copolymers containing methacrylic acid was $c a$. 3.4 and $6.6 \mathrm{~mol} \%$, and that of the polymer containing sulfonic acid, $4.1 \mathrm{~mol} \%$. The acid form samples in a benzenemethanol mixture were neutralized with methanolic sodium hydroxide.

The blends were prepared by the addition of organic sodium salts, sodium $p$-toluate and sodium $p$-toluenesulfonate, to ionomer solutions. Organic salts in blends were 10 and $30 \mathrm{wt} \%$. The solution was freeze-dried and dried further under vacuum at $150^{\circ} \mathrm{C}$ for one day. For dynamic mechanical property measurements, the samples were compression molded at $240^{\circ} \mathrm{C}$ with a pressure of $25 \mathrm{MPa}$. The molded samples, with approximate dimensions of $2.5 \times 6.0 \times 30.0 \mathrm{~mm}$, were annealed under vacuum at $170^{\circ} \mathrm{C}$ for one day.

\section{Dynamic Mechanical Thermal Analysis (DMTA)}

A Polymer Laboratories DMTA Mark II was used to determine the mechanical properties of ionomers. For each sample, the storage modulus $\left(E^{\prime}\right)$ and loss tangent $(\tan \delta)$ were obtained in a dual cantilever bending mode 
as a function of temperature at the heating rate of $1^{\circ} \mathrm{Cmin}^{-1}$.

\section{RESULTS AND DISCUSSION}

Figure 1 shows the storage modulus $\left(E^{\prime}\right)$ and loss tangent $(\tan \delta)$ curves of the poly(styrene-co-sodium methacrylate $)$ ionomer $(6.6 \mathrm{~mol} \%$ of ions $)$ [P(S-6.6$\mathrm{MANa})]$ and ionomers mixed with sodium $p$-toluate (Tol) and sodium p-toluenesulfonate (Sul). With increasing temperature the modulus curves show changes from glassy modulus, through matrix glass transition $\left(T_{\mathrm{g}, \mathrm{m}}\right)$, through ionic modulus, through cluster glass transition $\left(T_{\mathrm{g}, \mathrm{c}}\right)$, to rubbery modulus. The modulus in the intermediate region, in which the modulus value changes slightly with temperature, is the ionic modulus; which increased with organic salts added. Excess organic salts added may thus possibly be phase-separated to form micelle-type aggregates, which act as filler particles. As a result, filler particles increase the ionic modulus of ionomers.

At the same organic salt content the ionic modulus for blends containing the Tol molecules (MATol) is higher than that for blends containing the Sul molecules (MASul). For example, at $170^{\circ} \mathrm{C}$ the modulus for the ionomer is ca. $2.0 \times 10^{7} \mathrm{~Pa}$, while those for the ionomers containing $30 \mathrm{wt} \%$ of the Tol (MATol-30) and the Sul (MASul-30) are ca. $6.3 \times 10^{7} \mathrm{~Pa}$ and $c a .5 .0 \times 10^{7} \mathrm{~Pa}$, respectively. This can be explained based on molecular weights and ionic strengths of Tol and Sul salts. The molecular weight of Tol salt (formula weight $=158.1$ ) is lower than that of Sul salt (formula weight $=194.2$ ), and thus when the same amounts of organic salts are added to the ionomer, the number of salt molecules is larger for the Tol salt than for the Sul salt. Thus, if the number of salt molecules per micelle is the same for Tol and Sul salts, the number of micelles consisting of excess organic salts is larger for the Tol salt than for the Sul salt. However, ionic strength in sodium-carboxylate pairs is weaker than that in sodium-sulfonate pairs, and thus the number of ionic groups per micelle should be larger for the Sul case than for the Tol case. ${ }^{10}$ In this case, the number of micelles should also be larger for Tol than for Sul. These two factors may thus contribute to the larger number of micelles, leading to higher ionic modulus for the MATol samples than for MASul.

In Figure 1, two $\tan \delta$ peaks are seen; one at lower temperatures due to the matrix $T_{\mathrm{g}}$, and the other at higher temperatures to the cluster $T_{\mathrm{g}}$. To obtain more precise data for the $\tan \delta$ peaks, we used the Jandel Scientific Peakfit ${ }^{\circledR}$ computer program for curve deconvolution. ${ }^{11}$ The best fits were achieved taking an exponential function as the baseline and fitting the data for the matrix and cluster $\tan \delta$ peaks with exponentially modified Gaussian functions. In the present study there is no fundamental scientific significance to most of the parameters obtained from curve fitting of the $\tan \delta$ peaks, except for the center of the peak for the exponentially modified Gaussian, which corresponds to $T_{\mathrm{g}}$. The deconvolution results are listed in Table I. The matrix $T_{\mathrm{g}}$ of the $\mathrm{P}(\mathrm{S}-6.6-\mathrm{MANa})$ ionomer is $c a .133^{\circ} \mathrm{C}$, and the cluster $T_{\mathrm{g}} c a .198^{\circ} \mathrm{C}$. In the case of ionomers containing organic salts, the matrix $T_{\mathrm{g}}$ decreases slightly whereas the cluster $T_{\mathrm{g}}$ drops

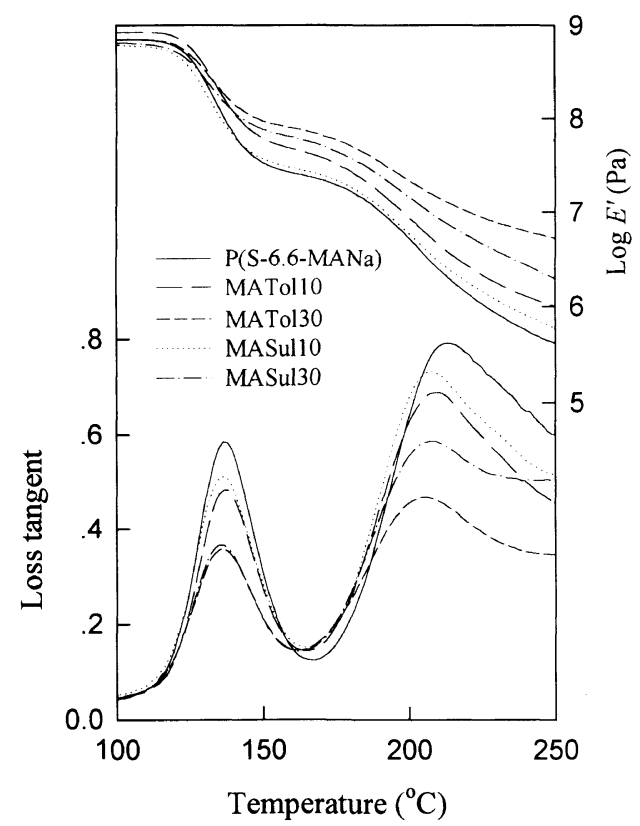

Figure 1. Storage modulus and loss tangent as functions of temperature for $\mathrm{P}(\mathrm{S}-6.6-\mathrm{MANa})$ ionomer and blends with sodium $p$-toluate (MATol) and sodium $p$-toluenesulfonate (MAsul) salts, measured at $1 \mathrm{~Hz}$.

Table I. Peak-fit results for the $\tan \delta$ peaks of ionomers and blends containing organic salts

\begin{tabular}{|c|c|c|c|c|c|}
\hline \multirow{3}{*}{ Ionomers } & \multicolumn{5}{|c|}{ Peak-fit parameters } \\
\hline & $T_{\mathrm{g}, \mathrm{m}}^{\mathrm{a}}$ & $T_{\mathrm{g}, \mathrm{c}} \mathrm{b}$ & $A_{\mathrm{m}}^{\mathrm{c}}$ & $A_{\mathrm{c}}^{\mathrm{d}}$ & $A_{\text {total }}{ }^{\mathrm{e}}$ \\
\hline & ${ }^{\circ} \mathrm{C}$ & ${ }^{\circ} \mathrm{C}$ & ${ }^{\circ} \mathrm{C}$ & ${ }^{\circ} \mathrm{C}$ & ${ }^{\circ} \mathrm{C}$ \\
\hline $\mathrm{P}(\mathrm{S}-6.6-\mathrm{MANa})$ & 133 & 198 & 12.8 & 32.6 & 45.4 \\
\hline MATol-10 & 132 & 195 & 10.2 & 28.0 & 38.2 \\
\hline MATol-30 & 130 & 188 & 8.8 & 20.2 & 29.0 \\
\hline MASul-10 & 131 & 193 & 10.9 & 28.1 & 39.0 \\
\hline MASul-30 & 130 & 189 & 7.7 & 24.4 & 32.1 \\
\hline $\mathrm{P}(\mathrm{S}-4.6-\mathrm{SSNa})$ & 125 & 253 & 29.7 & 30.7 & 60.4 \\
\hline SATol-10 & 125 & 244 & 22.4 & 32.1 & 54.6 \\
\hline SATol-30 & 124 & 246 & 16.2 & 28.2 & 44.4 \\
\hline SASul-10 & 124 & 244 & 21.7 & 31.6 & 53.3 \\
\hline SASul-30 & 124 & 246 & 16.9 & 27.0 & 43.9 \\
\hline
\end{tabular}

${ }^{\mathrm{a}}$ Center of matrix $\tan \delta$ peak. ${ }^{\mathrm{b}}$ Center of cluster $\tan \delta$ peak. ${ }^{\mathrm{c}}$ Area under matrix $\tan \delta$ peak. ${ }^{\mathrm{d}}$ Area under cluster $\tan \delta$ peak. ${ }^{\mathrm{e}} A_{\mathrm{m}}+A_{\mathrm{c}}$

significantly. For example, in the MATol-30 sample, drops in the matrix and cluster $T_{\mathrm{g}} \mathrm{s}$ are $c a .3$ and $10^{\circ} \mathrm{C}$, respectively. This is due to plasticization of the organic salts. When the organic salts participate in multiplet formation with ionic groups of the ionomer, tolyl groups reside in the restricted mobility regions surrounding the multiplets. This leads to more room for the polymer chains to move around in the clustered regions. As a result, the cluster $T_{\mathrm{g}}$ decreases. The cluster $T_{\mathrm{g}} \mathrm{s}$ of the blends containing the Tol and the Sul salts are very similar. Thus, the plasticization of the Tol and the Sul salts on the glass transitions of blends seems the same. This means that in blends, the sizes and stability of multiplets, consisting either of carboxylates groups of the salts and the ionomer or of carboxylate groups of the ionomer and sulfonate groups of the salts, are similar.

The modulus and $\tan \delta$ curves for the sulfonated 


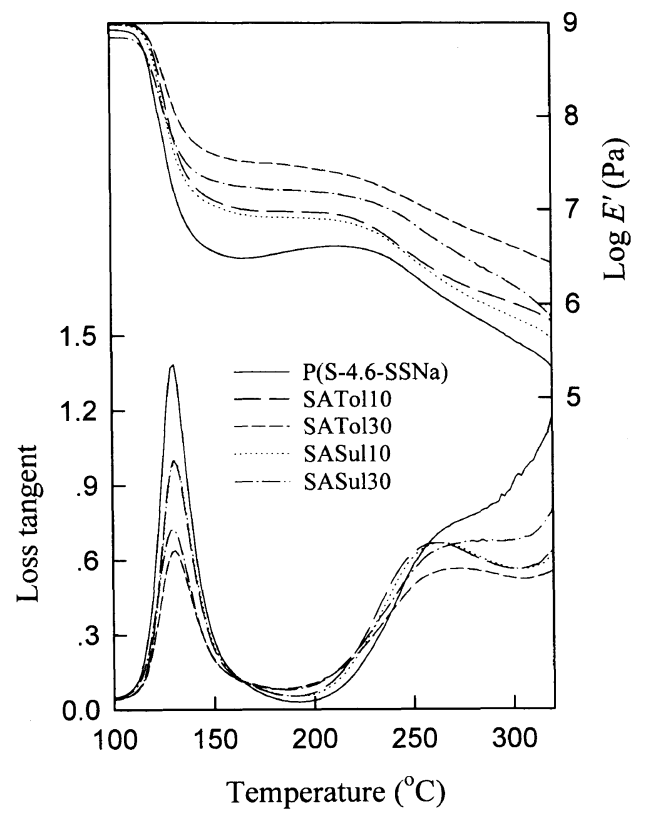

Figure 2. Storage modulus and loss tangent as functions of temperature for $\mathrm{P}(\mathrm{S}-4.6-\mathrm{SSNa})$ ionomer and blends with Tol salts (SATol) and Sul salts (SASul), measured at $1 \mathrm{~Hz}$.

polystyrene ionomer containing $4.6 \mathrm{~mol} \%$ of ions $[\mathrm{P}(\mathrm{S}$ 4.6-SSNa)] and its blends with organic salts are seen in Figure 2. As seen above, the ionic moduli increase as the amount of organic salts added increases. For example, at $170^{\circ} \mathrm{C}$, the ionic modulus for the $\mathrm{P}(\mathrm{S}-4.6$ $\mathrm{SSNa}$ ) is $c a .3 .2 \times 10^{6} \mathrm{~Pa}$ while those for the ionomers containing $30 \mathrm{wt} \%$ of the toluate (SATol-30) and toluenesulfonate (SASul-30) are $3.2 \times 10^{7} \mathrm{~Pa}$ and $1.6 \times 10^{7}$ $\mathrm{Pa}$, respectively. As observed above in the methacrylate system, with increasing the organic salt content, the cluster $T_{\mathrm{g}}$ peak shifts to lower temperatures. This is also due to plasticization. Similar results were also observed by Orler $e t a l^{7}$ The deconvolution results of $\tan \delta$ peaks are listed in Table I. Since the cluster $\tan \delta$ peaks were not well developed, there might well be some error in $T_{\mathrm{g}, \mathrm{c}}$ obtained from the peak fitting for the sulfonate system. However, the decreasing trend of the cluster $T_{\mathrm{g}}$ with increasing organic salts is clear.

From Figures 1 and 2, in the sulfonate system, increase in the ionic modulus by adding organic salts to ionomers is more substantial than in the methacrylate system. Under the assumption that areas under the $\tan \delta$ peaks for the matrix and cluster regions represent amounts of the regions, ${ }^{12,13}$ the amounts of clustered regions of the $\mathrm{P}(\mathrm{S}-6.6-\mathrm{MANa})$ and $\mathrm{P}(\mathrm{S}-4.6-\mathrm{SSNa})$ are $c a .70$ and $50 \%$, respectively. This implies that the filler effect of the excess organic salts on the ionic modulus may be stronger for the less clustered ionomer, i.e., the sulfonated ionomer.

To confirm the dependence of the amount of clustered material on the filler effect, we prepared P(S-co-MANa) ionomer containing $3.4 \mathrm{~mol} \%$ of sodium methacrylate groups [P(S-3.4-MANa)] and its blends containing Tol salts. The dynamic mechanical results are shown in Figure 3. After curve deconvolution, the amount of clustered material in this ionomer is $c a .45 \%$. The filler effect on the ionic modulus is stronger than that in the $\mathrm{P}(\mathrm{S}-6.6-\mathrm{MANa})$ ionomer system. Since cluster regions act as fillers in ionomer system, ${ }^{13}$ filler effect due to the

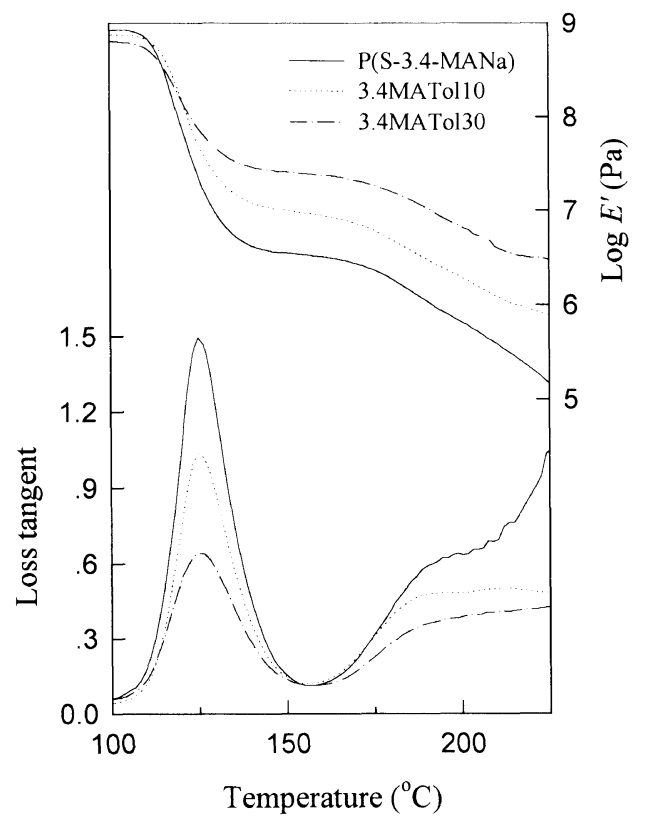

Figure 3. Storage modulus and loss tangent as functions of temperature for $\mathrm{P}(\mathrm{S}-3.4-\mathrm{MANa})$ ionomer and sodium $p$-toluate (3.4MATol) blends, measured at $1 \mathrm{~Hz}$.

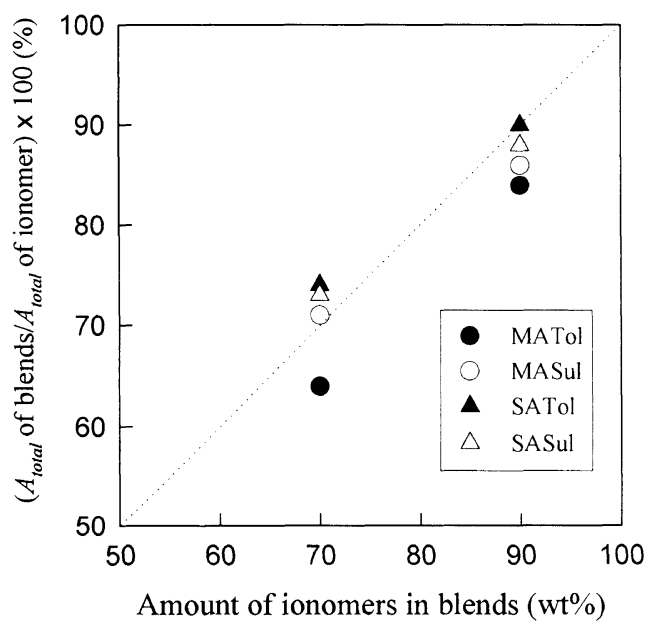

Figure 4. Percentages of (areas under the $\tan \delta$ peaks of blends/area under the $\tan \delta$ peaks of ionomers) vs. wt $\%$ ionomers in blends. Dotted line indicates $1: 1$ relationship.

presence of clusters becomes stronger with increasing ion content. Thus, the $\mathrm{P}(\mathrm{S}-6.6-\mathrm{MANa})$ ionomer should show stronger filler behavior by clustering than the $\mathrm{P}(\mathrm{S}-3.4-$ MANa) ionomer. Therefore, the apparent filler effect due to the addition of organic salts may be stronger in less clustered ionomers.

In Table I, total areas under $\tan \delta$ peaks $\left(A_{\text {total }}\right)$ decrease as amounts of organic salts increase. If the area under the $\tan \delta$ peak represents the relative amount of material causing the glass transitions, $A_{\text {total }}$ must decrease with amount of organic salt. Figure 4 shows the percentages of ( $A_{\text {total }}$ of blends/ $A_{\text {total }}$ of ionomers) against wt $\%$ of ionomers in blends. This figure shows an unambiguous linear relationship of the data with experimental error. Thus possibly, in polystyrene ionomer blends, the ratio of the total area under the $\tan \delta$ peaks may represent the relative amounts of styrene ionomers in the blends. 
Acknowledgment. The authors thank the reviewers for their valuable suggestions.

\section{REFERENCES AND NOTES}

1. A. Eisenberg and M. King, "Ion-Containing Polymer, Physical Properties and Structure," Academic Press, New York, N.Y. 1977.

2. A. Eisenberg and J.-S. Kim, "Introduction to Ionomers," Wiley, New York, N.Y., 1998.

3. A. Eisenberg, Macromolecules, 3, 147 (1970).

4. A. Eisenberg, B. Hird, and R. B. Moore, Macromolecules, 23, 4098 (1990).

5. C. G. Bazuin, In "Multiphase Polymers: Blends and Ionomers," L. A. Utracki and R. A. Weiss, Ed., ACS Symposium Series 395 , American Chemical Society, Washington, D.C., 1989, Chapter 21.

6. J.-S. Kim, S. B. Roberts, A. Eisenberg, and R. B. Moore,
Macromolecules, 26, 5256 (1993).

7. E. B. Orler, B. H. Calhoun, and R. B. Moore, to be published.

8. X. Tong and C. G. Bazuin, Chem. Mater., 4, 370 (1992).

9. H. S. Makowski, R. D. Lundberg, and G. L. Singhal, U.S. Patent 3870841 (1975)

10. B. Hird and A. Eisenberg, Macromolecules, 25, 6466 (1992).

11. The readers, who are interested in peak deconvolution, are referred to the standard textbook such as N. G. McCrum, B. E. Read, and G. Williams, "Anelastic and Dielectric Effects in Polymeric Solids," John Wiley and Sons, New York, N.Y., 1967 and several articles such as M. Takayanagi and N. Kawasaki, J. Macromol. Sci.-Phys., B1, 741 and M. C. O. Chang, D. A. Thomas, and L. H. Sperling, J. Appl. Polym. Sci., 34, 409 (1987); J. Polym. Sci. Polym. Phys. Ed., 26, 1627 (1988).

12. B. Hird and A. Eisenberg, J. Polym. Sci., Polym. Phys. Ed., 28, $1655(1990)$

13. J.-S. Kim, R. J. Jackman, and A. Eisenberg, Macromolecules, 27, 2789 (1994). 